\title{
Prevalence of Juvenile Fibromyalgia Syndrome Among Children and Adolescents and its Relationship With Academic Success, Depression and Quality of Life, Çorum Province, Turkey
}

\author{
Ayla ÇAGLIYAN TÜRK ${ }^{1}$, Füsun ŞAHİN²D \\ ${ }^{1}$ Department of Physical Medicine and Rehabilitation, Hitit University Faculty of Medicine, Çorum, Turkey \\ ${ }^{2}$ Department of Physical Medicine and Rehabilitation, Pamukkale University, Faculty of Medicine, Denizli, Turkey
}

\begin{abstract}
Objectives: This study aims to determine the frequency of juvenile fibromyalgia syndrome (JFMS) among children and adolescents in Çorum Province, Turkey, and its impact by comparing the levels of academic success, depression and quality of life (QoL) in individuals with and without JFMS.

Patients and methods: This was a cross-sectional study on 476 children and adolescents (245 boys, 231 girls; mean age 13.81 \pm 2.3 years; range, 9 to 17 years). The control group (non-JFMS group) consisted of 105 age- and sex-matched healthy participants (75 girls, 30 boys; mean age $14.1 \pm 1.8$ years; range; 9 to 17 years). Participants' sociodemographic data, parental information, and school achievement in addition to data on chronic illness and drug use were collected via questionnaires (depression and QoL). A tender point (TP) examination was performed on each participant.

Results: Thirty-five (7.35\%) of the participants (girls, $n=25$; boys, $n=10$ ) were diagnosed with JFMS. The number of minor JFMS diagnostic criteria, number of TPs, depression level and number of days the participants were absent from school were significantly higher in the JFMS group compared with the non-JFMS group $(p<0.05)$. The mean grade point scores of the JFMS group were significantly lower than those of the non-JFMS group $(p<0.05)$. The QoL subgroup scores as assessed by physical functioning, emotional functioning, social functioning and school-related problems of the JFMS group were significantly lower than the non-JFMS group $(p<0.05)$. Age had a statistically significant negative correlation with QoL and school-related problems $(r=-0.421, r=-0.494 ; p<0.05$, respectively). Depression was negatively correlated with QoL and school-related problems $(r=-0.672, r=-0.731 ; p<0.05$, respectively).

Conclusion: Juvenile fibromyalgia syndrome affects QoL and can lead to school absenteeism, poor academic performance, depression and anxiety among the school-age population. Early identification of JFMS and early intervention may be the most effective strategy for preventing problems in later life.

Keywords: Depression, juvenile fibromyalgia syndrome, quality of life, school absenteeism, school success.
\end{abstract}

Juvenile fibromyalgia syndrome (JFMS) is an idiopathic chronic pain syndrome that occurs in children and adolescents, particularly teenage girls. JFMS is associated with extra-articular musculoskeletal system pain and specific tender points (TPs). Additional common symptoms include sleeping difficulties, fatigue, irritable bowel syndrome, mood swings, subjective soft tissue swelling and headaches. JFMS begins in youngsters and is increasingly diagnosed in adolescents. ${ }^{1-3}$ At present, 2-6.1\% of school-age children are thought to have JFMS. ${ }^{4,5}$

Juvenile fibromyalgia syndrome often persists for years without diagnosis, with most patients referred to specialists for chronic headaches and chest or abdominal pain symptoms. Furthermore,

Received: February 20, 2019 Accepted: April 08, 2019 Published online: November 25, 2019

Correspondence: Ayla Çağlıyan Türk, MD. Hitit Üniversitesi Tıp Fakültesi Fiziksel Tıp ve Rehabilitasyon Anabilim Dalı, 19040 Çorum, Turkey. Tel: +90 533 - 4314171 e-mail: drayla1976@hotmail.com 
costly assessments show normal findings. ${ }^{6}$ Although fibromyalgia syndrome (FMS) is the known lead to important morbidity in adults, its effects in childhood were not well known until recently with studies on the topic beginning to emerge. ${ }^{1-3,7}$ As FMS can be associated with chronic somatic and psychological symptoms in adults, it is important that it is correctly identified and treated during adolescence. , $^{6,8}, 9$

As acknowledged in the literature, increased pain, fatigue, and depression symptoms and reduced quality of life (QoL) are seen in children with JFMS compared to healthy children and children with rheumatic disorders. ${ }^{4,10}$ In a previous study, children with chronic pain and their caregivers experienced significant decrease in QoL while anxiety and depression were also common in these individuals. ${ }^{11}$ The frequency of certain psychological disorders in patients with JFMS is unknown. Patients with JFMS also have mild anxiety, such as in children with other chronic pain conditions including juvenile idiopathic arthritis or chronic low back pain. Severe mood disorders can also be seen in children with JFMS. ${ }^{6}$

Increased school absenteeism and declined academic success have been documented in youth with chronic pain.7,12,13 School absenteeism was reported to be nine days for adolescents with primary pain, whereas 1.7 days absenteeism was reported for those with juvenile arthritis. ${ }^{13}$ In one study, $14 \%$ of patients reported three months or more of school absenteeism. A community-based study revealed similar findings, with $49 \%$ of those aged 4-18 years who had chronic pain in the previous three months absent from school due to pain and absenteeism increasing with age. ${ }^{14}$

In this study, we aimed to determine the frequency of JFMS among children and adolescents in Çorum Province, Turkey, and its impact by comparing the levels of academic success, depression and QoL in individuals with and without JFMS.

\section{PATIENTS AND METHODS}

This cross-sectional study was conducted at Hitit University Faculty of Medicine on 476 children and adolescents (245 boys, 231 girls; mean age
$13.81 \pm 2.3$ years; range, 9 to 17 years) attending secondary schools and high schools in Çorum Province, Turkey, between September 2017 and June 2018. There are 42 secondary schools and 29 high schools in the city center with a total of 51,539 students. The sample size was calculated according to these numbers and at least 380 were found. A researcher then attended the schools at a specified date and time to gather the data. The control group (non-JFMS group) consisted of 105 age- and sex-matched healthy students (75 girls, 30 boys; mean age $14.1 \pm 1.8$ years; range; 9 to 17 years). The study was performed by physical therapy and rehabilitation specialists. A physiatrist visited the schools to fill in the questionnaires and examine students. The study protocol was approved by the Hitit University Faculty of Medicine Ethics Committee. A written informed consent was obtained from parents of each participant. The study was conducted in accordance with the principles of the Declaration of Helsinki.

Cluster sampling was used in this study. The schools were first grouped according to their localization and two high schools and two secondary schools were selected. The study group was randomly selected from the total student list obtained from the school and the proportion was established by considering the number of sample and number of female/male students. Appropriate time for medical examination of the selected students was determined by the school principal.

The sociodemographic data of the participants and parental information were collected using questionnaires, which also recorded information on the presence of chronic illness and drug use. Depression and QoL were evaluated with the relevant questionnaire. Parents were also sent a separate questionnaire about QoL. Parents were asked to complete the questionnaire and send it to school.

Students were examined by evaluating sensitive points. TP examination was applied while the student was in sitting position. Approximately $4 \mathrm{~kg}$ force was applied using the index finger to the TP. The student was asked to say when she/he felt pain. The 18 TP regions (nine pairs) specified in the American College of Rheumatology criteria were evaluated: ${ }^{15}$ suboccipital muscle adhesion sites, the middle part of the upper edge of the trapezius muscle, the frontal sides of the 
intertransverse space at C5-7, the part near the inner margin over the scapular spine, second costochondral junction, $2 \mathrm{~cm}$ distal region of lateral epicondyle, the upper external quadrants of the gluteus in the anterior fold of the gluteal muscle, the area behind the greater trochanteric spine and medial fat pad of the knee.

Fibromyalgia was described according to the criteria of Yunus and Masi. ${ }^{16}$ Other than TPs, there were 10 additional minor criteria: chronic anxiety, fatigue, sleep disturbances, irritable bowel syndrome, subjective soft tissue swelling, headaches, numbness, pain affected by physical activity and weather-related changes and stress. JFMS was considered to be present with three minor criteria and five TPs or five minor criteria and four TPs.

The Children's Depression Scale (CDS) was used to evaluate depression levels. CDS is a self-assessment scale developed for children and adolescents between the ages of 6 and 17, while supervision may be required for small children. The scale contains 27 items, each of which having three options. The child chooses the most appropriate sentence based on the previous two weeks. Each item is scored as 0,1 or 2 regarding the severity of symptoms. The maximum total score is 54 , with a higher total score indicating a higher level of depression. The recommended cut-off point is $19 .{ }^{17}$ The reliability and validity of the Turkish version of the scale were confirmed previously. ${ }^{18}$

Quality of life was assessed using the Pediatric Quality of Life Inventory (PedsQL), developed in 1999 by Varni et al. ${ }^{19}$ PedsQL is a 23-item general QoL scale appropriate for use in large populations (e.g. in schools and hospitals) in healthy or sick children or adolescents. Each item is scored between 0 and 100. If the answer to a question is 'never', it receives a score of 100 , whereas responses of 'rarely', 'sometimes', 'often' and 'always' receive scores of 75, 50, 25 and 0 , respectively. Higher PedsQL total scores indicate better health-related QoL. ${ }^{20}$ The PedsQL questionnaire has parent and child forms for the 8-12 age group and parent and adolescent forms for the 13-18 age group. In this study, the parent form was completed by the caregiver, and the child/adolescent form was completed by the child/adolescent. Validity and reliability studies of the Turkish version of PedsQL were conducted previously for the two age groups. ${ }^{21,22}$

\section{Statistical analysis}

The IBM SPSS version 22.0 software (IBM Corp., Armonk, NY, USA) was used for the statistical analysis of the findings. The ShapiroWilk test was performed to determine the normality of the data distribution. The Student's t-test was used for comparisons between two groups of normally distributed quantitative parameters, and the Mann-Whitney U test was used for comparisons between two groups of non-normally distributed quantitative parameters, as well as for descriptive statistics (mean, standard deviation, frequency). A Chi-square test, Fisher's exact test, the Fisher-Freeman-Halton test and Yates's correction for continuity were used for the comparison of qualitative data. Pearson's correlation analysis and Pearson's correlation coefficient (rho) were conducted for parametric data, and Spearman's correlation analysis and Spearman's rho were performed for nonparametric data. Logistic regression analysis was applied for multivariate analysis. Significance was assessed at the $\mathrm{p}<0.05$ level.

Table 1. Demographic data

\begin{tabular}{|c|c|c|c|c|c|c|c|c|c|}
\hline & \multicolumn{4}{|c|}{ JFMS group } & \multicolumn{4}{|c|}{ Non-JFMS group (control group) } & \multirow[b]{2}{*}{$p$} \\
\hline & $\mathrm{n}$ & $\%$ & Mean \pm SD & Median & $\mathrm{n}$ & $\%$ & Mean \pm SD & Median & \\
\hline Age (year) & & & $14.8 \pm 2.3$ & & & & $14.1 \pm 1.8$ & & $0.091 \dagger$ \\
\hline \multicolumn{10}{|l|}{ Sex } \\
\hline Girl & 25 & 71.4 & & & 75 & 71.4 & & & \multirow{2}{*}{$1.000 \neq$} \\
\hline Boy & 10 & 28.6 & & & 30 & 28.6 & & & \\
\hline Body mass index & & & $20.5 \pm 3.5$ & & & & $19.1 \pm 3.0$ & & $0.026^{*} \dagger$ \\
\hline Class & & & $8.6 \pm 2.0$ & 9 & & & $7.9 \pm 1.7$ & 9 & $0.012 * \pi$ \\
\hline
\end{tabular}


Table 2. Evaluation of parental information among groups

\begin{tabular}{|c|c|c|c|c|c|c|c|}
\hline & \multicolumn{3}{|c|}{ JFMS group } & \multicolumn{3}{|c|}{ Non-JFMS group (control group) } & \multirow[b]{2}{*}{$p$} \\
\hline & $\mathrm{n}$ & $\%$ & Mean \pm SD & $\mathrm{n}$ & $\%$ & Mean \pm SD & \\
\hline Age of mother & & & $38.9 \pm 4.8$ & & & $39.5 \pm 4.5$ & $0.532 \dagger$ \\
\hline Age of father & & & $43.3 \pm 4.8$ & & & $43.8 \pm 5.5$ & $0.659 \dagger$ \\
\hline \multicolumn{8}{|l|}{ Education of mother } \\
\hline Primary school & 17 & 48,6 & & 27 & 25.7 & & \multirow{4}{*}{$0.055 \neq$} \\
\hline Middle school & 7 & 20 & & 20 & 19 & & \\
\hline High school & 7 & 20 & & 31 & 29.5 & & \\
\hline University & 4 & 11.4 & & 27 & 25.7 & & \\
\hline \multicolumn{8}{|l|}{ Education of father } \\
\hline Primary school & 11 & 31.4 & & 13 & 12.4 & & \multirow{4}{*}{$0.025^{*} \neq$} \\
\hline Middle school & 5 & 14.3 & & 9 & 8.6 & & \\
\hline High school & 10 & 28.6 & & 34 & 32.4 & & \\
\hline University & 9 & 25.7 & & 49 & 46.7 & & \\
\hline \multicolumn{8}{|l|}{ Job of mother } \\
\hline Housewife & 27 & 77.1 & & 73 & 69.5 & & \multirow[t]{2}{*}{0.5179} \\
\hline Active working & 8 & 22.9 & & 32 & 30.5 & & \\
\hline \multicolumn{8}{|l|}{ Job of father } \\
\hline Active working & 33 & 94.3 & & 98 & 93.3 & & \multirow[t]{2}{*}{$1.000 \S$} \\
\hline Retired & 2 & 5.7 & & 7 & 6.7 & & \\
\hline \multicolumn{8}{|l|}{ Single parent } \\
\hline No & 34 & 97.1 & & 103 & 98.1 & & \multirow{2}{*}{$1.000 \S$} \\
\hline Yes & 1 & 2.9 & & 2 & 1.9 & & \\
\hline
\end{tabular}

\section{RESULTS}

Thirty-five students (7.35\%) were diagnosed with JFMS and compared with the 105 nonJFMS control subjects. The demographic data of both groups were summarized in Table 1. There were no significant differences between the JFMS group and non-JFMS group in terms of mean age $(p=0.091)$ or sex distribution $(p=1.000)$. Body mass index (BMI) was significantly higher in the JFMS group than in the non-JFMS group $(p=0.026)$.

Data related to the parents of the students diagnosed with JFMS and those of the non-JFMS group were demonstrated in Table 2. There were

Table 3. Evaluation of various parameters between groups

\begin{tabular}{|c|c|c|c|c|c|c|c|c|c|}
\hline & \multicolumn{4}{|c|}{ JFMS group } & \multicolumn{4}{|c|}{ Non-JFMS group (control group) } & \multirow[b]{2}{*}{$p$} \\
\hline & $\mathrm{n}$ & $\%$ & Mean \pm SD & Median & $\mathrm{n}$ & $\%$ & Mean \pm SD & Median & \\
\hline Number of minor criteria & & & $5.6 \pm 1.8$ & 5 & & & $1.4 \pm 1.7$ & 1 & $0.001^{*} \dagger$ \\
\hline Number of tender points & & & $7.4 \pm 2.1$ & 7 & & & $1.5 \pm 2.5$ & 0 & $0.001^{*} \dagger$ \\
\hline Depression & & & $15.7 \pm 7.7$ & 16 & & & $9.0 \pm 5.2$ & 9 & $0.001^{*} \dagger$ \\
\hline School absenteeism & & & $10.0 \pm 6$ & 11 & & & $5.2 \pm 4.3$ & 4 & $0.001^{*} \dagger$ \\
\hline Grade point mean & & & $80.1 \pm 10.9$ & 78.1 & & & $85.7 \pm 10.0$ & 84.3 & $0.014 * \dagger$ \\
\hline Depression presence & 24 & 68.6 & & & 100 & 95.2 & & & $0.001^{*} \neq$ \\
\hline
\end{tabular}




\begin{tabular}{|c|c|c|c|c|c|}
\hline & \multicolumn{2}{|c|}{ JFMS group } & \multicolumn{2}{|c|}{$\begin{array}{l}\text { Non-JFMS group } \\
\text { (control group) }\end{array}$} & \multirow[b]{2}{*}{$p$} \\
\hline & $\mathrm{n}$ & $\%$ & $\mathrm{n}$ & $\%$ & \\
\hline \multicolumn{6}{|l|}{ Fatigue } \\
\hline No & 4 & 11.4 & 69 & 65.7 & \multirow{2}{*}{$0.001^{*} \dagger$} \\
\hline Yes & 31 & 88.6 & 36 & 34.3 & \\
\hline \multicolumn{6}{|c|}{ Sleep disturbance } \\
\hline No & 8 & 22.9 & 79 & 75.2 & \multirow{2}{*}{$0.001^{*} \dagger$} \\
\hline Yes & 27 & 77.1 & 26 & 24.8 & \\
\hline \multicolumn{6}{|c|}{ Chronic anxiety or tension } \\
\hline No & 8 & 22.9 & 92 & 87.6 & \multirow{2}{*}{$0.001^{*} \dagger$} \\
\hline Yes & 27 & 77.1 & 13 & 12.4 & \\
\hline \multicolumn{6}{|c|}{ Chronic headaches } \\
\hline No & 15 & 42.9 & 94 & 89.5 & \multirow{2}{*}{$0.001^{*} \dagger$} \\
\hline Yes & 20 & 57.1 & 11 & 10.5 & \\
\hline \multicolumn{6}{|c|}{ Irritable bowel syndrome } \\
\hline No & 31 & 88.6 & 104 & 99 & \multirow{2}{*}{$0.014^{*} \neq$} \\
\hline Yes & 4 & 11.4 & 1 & 1 & \\
\hline \multicolumn{6}{|c|}{ Subjective soft tissue swelling } \\
\hline No & 29 & 82.9 & 104 & 99 & \multirow{2}{*}{$0.001^{*} \ddagger$} \\
\hline Yes & 6 & 17.1 & 1 & 1 & \\
\hline \multicolumn{6}{|c|}{ Numbness or tingling of the extremities } \\
\hline No & 14 & 40 & 93 & 88.6 & \multirow{2}{*}{$0.001^{*} \dagger$} \\
\hline Yes & 21 & 60 & 12 & 11.4 & \\
\hline \multicolumn{6}{|c|}{ Pain modulated by weather } \\
\hline No & 25 & 71.4 & 98 & 93.3 & \multirow{2}{*}{$0.002^{*} \dagger$} \\
\hline Yes & 10 & 28.6 & 7 & 6.7 & \\
\hline \multicolumn{6}{|c|}{ Pain modulated by physical activity } \\
\hline No & 12 & 34.3 & 81 & 77.1 & \multirow{2}{*}{$0.001^{*} \dagger$} \\
\hline Yes & 23 & 65.7 & 24 & 22.9 & \\
\hline \multicolumn{6}{|c|}{ Pain modulated by stress or anxiety } \\
\hline No & 11 & 31.4 & 83 & 79 & \multirow{2}{*}{$0.001^{*} \dagger$} \\
\hline Yes & 24 & 68.6 & 22 & 21 & \\
\hline
\end{tabular}

no significant between-group differences in terms of maternal or paternal ages, maternal education levels or distribution ratios of maternal occupation, paternal occupation or parental divorce. The fathers of the students in the JFMS group had lower levels of education (primary school education only) $(31.4 \%$ vs. $12.4 \%) \quad(p=0.025)$ (Table 2).

The number of TPs and minor diagnostic criteria, depression levels and number of school absences were significantly higher in the JFMS group than in the non-JFMS group $(p=0.001)$.
The mean school grade scores of the JFMS group were statistically lower than those of the nonJFMS group $(p=0.014)$ (Table 3$)$.

The between-group comparison of minor diagnostic criteria revealed a statistically significantly higher number in the JFMS group than in the non-JFMS group $(p=0.001)$ (Table 4).

When the mean QoL and specific aspects of QoL (i.e. physical, emotional and social functioning and school-related problems) were assessed, the QoL of the JFMS group was significantly lower than non-JFMS group $(p=0.001)$. However, 
Table 5. Assessing total and subgroup levels of children's quality of life according to children and parents

\begin{tabular}{|c|c|c|c|c|c|}
\hline & \multicolumn{2}{|c|}{ JFMS group } & \multicolumn{2}{|c|}{ Non-JFMS group (control group) } & \multirow[b]{2}{*}{$p \dagger$} \\
\hline & Mean \pm SD & Median & Mean \pm SD & Median & \\
\hline \multicolumn{6}{|l|}{ PedsQL } \\
\hline Total quality of life & $1,538.6 \pm 300.6$ & 1525 & $1,910.5 \pm 250.0$ & 1950 & $0.001^{*}$ \\
\hline Physical functionality & $527.1 \pm 134$ & 525 & $675.5 \pm 103.1$ & 700 & $0.001^{*}$ \\
\hline Emotional functionality & $276.4 \pm 103.4$ & 300 & $391.9 \pm 78.1$ & 400 & $0.001^{*}$ \\
\hline Social functionality & $431.4 \pm 67.6$ & 450 & $462.9 \pm 52.6$ & 475 & $0.006^{*}$ \\
\hline School problems & $301.4 \pm 92.3$ & 300 & $387.6 \pm 77.3$ & 375 & $0.001^{*}$ \\
\hline \multicolumn{6}{|c|}{ Parental assessment of PedsQL } \\
\hline Total quality of life & $1,745 \pm 339.9$ & 1775 & $1,892.0 \pm 282.5$ & 1950 & 0.099 \\
\hline Physical functionality & $585 \pm 148.3$ & 600 & $628.2 \pm 146.7$ & 675 & 0.206 \\
\hline Emotional functionality & $350 \pm 101.6$ & 362.5 & $391.4 \pm 81.2$ & 400 & 0.090 \\
\hline Social functionality & $436.3 \pm 114.8$ & 475 & $463.8 \pm 53.1$ & 475 & 0.399 \\
\hline School problems & $348.8 \pm 101.8$ & 375 & $412.2 \pm 76.8$ & 425 & $0.011^{*}$ \\
\hline
\end{tabular}

parental evaluation revealed that the JFMS group had significantly lower levels in the school-related problems subgroup compared to the control group $(p=0.011)$ (Table 5).

There was a negative correlation between age and QoL ( $\mathrm{r}=-0.421, \mathrm{p}=0.012)$ and school-related problems $(\mathrm{r}=-0.494, \mathrm{p}=0.003)$. Also, there was a negative correlation between depression and childhood QoL ( $\mathrm{r}=-0.672, \mathrm{p}=0.001)$ and school-related problems $(r=-0.731, p=0.001)$.
There was a positive correlation between grade score means and QoL $(\mathrm{r}=0.432, \mathrm{p}=0.010)$. There was a negative correlation between maternal age and the number of TPs $(r=-0.547, p=0.001)$ (Table 6).

The effects of school grade, absenteeism, mean grade scores, depression, total QoL, physical, emotional and social functioning, school problems, fatigue, sleep disorders, tension, headaches, subjective soft tissue swelling, increased physical

Table 6. Correlation of some variables in JFMS group

\begin{tabular}{|c|c|c|c|c|c|c|}
\hline & PedsQL & School problems & $\begin{array}{c}\text { Physical } \\
\text { functionality }\end{array}$ & $\begin{array}{l}\text { Emotional } \\
\text { functionality }\end{array}$ & $\begin{array}{l}\text { Number of } \\
\text { minor criteria }\end{array}$ & $\begin{array}{l}\text { Number of } \\
\text { tender points }\end{array}$ \\
\hline \multicolumn{7}{|l|}{ Age } \\
\hline$r$ & -0.421 & -0.494 & -0.321 & -0.184 & -0.073 & 0.063 \\
\hline $\mathrm{p}$ & $0.012^{*}$ & $0.003^{*}$ & 0.06 & 0.29 & 0.675 & 0.720 \\
\hline \multicolumn{7}{|c|}{ Age of mother } \\
\hline$r$ & 0.265 & 0.190 & 0.359 & 0.208 & -0.547 & 0.193 \\
\hline $\mathrm{p}$ & 0.124 & 0.275 & $0.034^{*}$ & 0.231 & $0.001^{*}$ & 0.266 \\
\hline \multicolumn{7}{|c|}{ Grade score mean } \\
\hline r & 0.432 & 0.482 & 0.318 & 0.150 & -0.06 & 0.009 \\
\hline $\mathrm{p}$ & $0.010^{*}$ & $0.003^{*}$ & 0.063 & 0.391 & 0.734 & 0.957 \\
\hline \multicolumn{7}{|c|}{ Depression } \\
\hline r & -0.672 & -0.731 & -0.316 & -0.646 & 0.183 & 0.094 \\
\hline $\mathrm{p}$ & $0.001^{*}$ & $0.001^{*}$ & 0.064 & $0.001^{*}$ & 0.293 & 0.59 \\
\hline \multicolumn{7}{|c|}{ School absenteeism } \\
\hline $\mathrm{r}$ & 0.032 & 0.074 & -0.088 & 0.186 & -0.231 & 0.206 \\
\hline $\mathrm{p}$ & 0.857 & 0.672 & 0.617 & 0.284 & 0.182 & 0.236 \\
\hline
\end{tabular}




\begin{tabular}{|c|c|c|c|c|}
\hline & \multirow[b]{2}{*}{ OR } & \multicolumn{2}{|c|}{$95 \%$ CI for OR } & \multirow[b]{2}{*}{$p$} \\
\hline & & Lower & Upper & \\
\hline School absenteeism & 1.139 & 1.006 & 1.29 & $0.040^{*}$ \\
\hline Emotional functionality & 0.989 & 0.982 & 0.996 & $0.002^{*}$ \\
\hline Fatigue & 4.845 & 1.088 & 21.582 & $0.038^{*}$ \\
\hline Chronic anxiety or tension & 8.789 & 2.419 & 31.93 & $0.001^{*}$ \\
\hline Numbness or tingling of the extremities & 8.83 & 2.345 & 33.242 & $0.001^{*}$ \\
\hline Constant & 0.358 & & & 0.418 \\
\hline
\end{tabular}

activity and stress-related parameters on JFMS were evaluated using backward stepwise logistic regression analysis. The Nagelkerke $\mathrm{R}$ square value was 0.714 , and the explanatory coefficient of the model was good (89.3\%). According to the model, the effects of absenteeism, emotional functioning, fatigue, tension and numbness were statistically significant, with absenteeism, emotional functioning, fatigue, tension and numbness having a 1.139, 0.989, 4.845, 8.789 and 8.830 times disease-enhancing effect, respectively (Table 7).

\section{DISCUSSION}

In our study, JFMS was detected in $7.35 \%$ of the students in Çorum province. Among the students with JFMS, depression and school absences were higher and school performance and QoL were lower compared with the control students.

Studies investigating the prevalence of JFMS in the literature are very limited. Studies conducted in various countries found that the prevalence of JFMS in school children varied from 1.2 to $6.2 \% .{ }^{23-25}$ JFMS has been reported in $7-15 \%$ of patients applying to pediatric rheumatology clinics. ${ }^{4}$ Discord in the reported rate of fibromyalgia may be the result of differences in populations, methodology and diagnostic criteria. In our study, the diagnosis of JFMS was established according to the Yunus and Masi criteria ${ }^{16}$ and our results were similar to the literature.

Children with JFMS experience severe pain, which contributes to the emergence of other symptoms, such as fatigue, sleep disturbance, stress, anxiety and depression. ${ }^{3}$ Fatigue is a subjective manifestation of many chronic conditions, including neurological and inflammatory conditions. Previous research reported that fatigue and non-restorative sleep were relatively common in FMS and that they contributed to increased levels of functional impairment. ${ }^{26}$ Fatigue was reported in $96.7 \%$ of FMS patients, and $68.9 \%$ of patients reported sleep disturbances. ${ }^{7}$ Symptoms associated with fibromyalgia include non-restful sleep (100\%), fatigue (91\%), chronic anxiety (56\%), chronic headache (54\%) and subjective soft tissue swelling (61\%). ${ }^{16}$ Similarly, in the present study, JFMS patients had high rates of fatigue, sleep disturbances/tension and headaches (88.6\%, $77.1 \%$ and $57.1 \%$, respectively). The most common factors associated with JFMS are chronic anxiety, numbness or tingling in the extremities and fatigue. ${ }^{31}$ Lynch-Jordan et al. ${ }^{27}$ found similar findings in a study on 94 JMFS patients. The same study indicated that pain severity and perceived social support were important parameters in predicting depressive symptoms. In another study, $78 \%$ of JFMS patients were diagnosed with at least one psychiatric disturbance. ${ }^{8}$ In addition, the most common psychiatric diagnoses were anxiety disorders (46.2\%). Arnold et al. ${ }^{25}$ reported that the rate of depression in those with JFMS was $16.4 \%$, whereas Durmaz et al. ${ }^{7}$ reported a figure of $42.6 \%$. The rate of depression in the JFMS group in the present study was $31.4 \%$, which was significantly higher in the control group.

Patients with chronic pain experience functional difficulty in their everyday activities. These difficulties lead to limitations in their social lives, including social interactions. ${ }^{27}$ In common 
with other patients with chronic pain, previous research demonstrated that individuals with JFMS experience decreased QoL. ${ }^{28}$ For example, Durmaz et al. ${ }^{7}$ found a significantly lower QoL in children with JFMS. Kashikar-Zuck et al. ${ }^{29}$ reported significant difficulty in daily QoL in adolescents and children with chronic pain, such as JFMS and back pain. This study also demonstrated that psychological distress caused emotion-focused avoidance as a coping strategy and that this coping strategy was associated with increased disability levels in children. ${ }^{29}$ In our study, the QoL of the students with JFMS was significantly lower than the non-JFMS group when the subgroups were assessed. However, according to the parents' assessment, only school-related problems were lower than in the non-JFMS group in terms of QoL.

School attendance is an important factor in the development of children and adolescents. A previous long-term follow-up study showed that school absenteeism causes economic, social and psychiatric problems in adulthood. ${ }^{30,31}$ Research also showed that recurrent school absences in patients with chronic pain can lead to significant functional impairments, such as decreased academic performance and a decreased ability to cope with school-related difficulties. ${ }^{13}$ Previous studies on adolescents with JFMS reported school absenteeism figures of 2.88 days per month. ${ }^{32}$ and 22.6 days per academic year. ${ }^{33}$ Pain-related conditions, such as fatigue, headaches, an irritable bowel, dysmenorrhea and sleep problems, were found to be the most frequent reasons associated with school absenteeism and the most common psychiatric disorder associated with school absenteeism was depression. ${ }^{32}$ However, some studies suggested that school absences were not always related to pain intensity or psychological variables.7,34 In our study, school absenteeism (11 days per year) was significantly higher in the JFMS group. However, there was no relationship between absenteeism and depression, QoL and the number of TPs.

In terms of the effect of chronic pain on children's performance in school, some studies reported that it negatively affected functioning, ${ }^{15,34}$ whereas other studies reported no such effect. ${ }^{29,33}$ Some of these studies reported that child-specific psychosocial factors and the child's parents played more important roles than pain did in the child's performance (functioning) in school. ${ }^{29,33}$ However, Logan et al. ${ }^{35}$ reported that many adolescents with chronic pain between the ages 12 and 17 years had high levels of school absenteeism, poor grades and decreased school success due to perceived pain. Durmaz et al. ${ }^{7}$ also reported that school performance was low in patients with JFMS. In the present study, school success was significantly lower in the JFMS group compared with that in the non-JFMS group. Although QoL affected academic success in school, depression, the number of TPs and the presence of minor diagnostic criteria were not associated with school achievements.

Our study demonstrated that the JFMS group had higher BMIs. Bennett et al. ${ }^{36}$ reported that $70 \%$ of 2,596 adult FMS patients had BMIs greater than $25 \mathrm{~kg} / \mathrm{m} 2$ and $43 \%$ had BMIs greater than $30 \mathrm{~kg} / \mathrm{m} 2$. In another study, $44.7 \%$ of FMS patients were obese and $36.8 \%$ were overweight. ${ }^{37}$ These issues need to be investigated in JFMS.

There are some limitations of our study. The most important is that JMFS was diagnosed based on a clinical point of view, and no laboratory tests were performed. Some symptoms of fibromyalgia, such as insomnia and fatigue, are general and may be caused by multiple medical conditions. Such conditions could not be excluded due to the nature of the study that involved a school-based setting.

In conclusion, JFMS may have negative effects on the QoL of school-age children and may lead to school absenteeism, poor academic performance, depression and anxiety. Early identification of JFMS and early interventions may be the most effective strategy to prevent problems that may arise in adulthood.

\section{Declaration of conflicting interests}

The authors declared no conflicts of interest with respect to the authorship and/or publication of this article.

\section{Funding}

The authors received no financial support for the research and/or authorship of this article.

\section{REFERENCES}

1. Zemel L, Blier PR. Juvenile Fibromyalgia: A Primary Pain, or Pain Processing, Disorder. Semin Pediatr Neurol 2016;23:231-41. 
2. Gmuca S, Sherry DD. Fibromyalgia: Treating pain in the juvenile patient. Paediatr Drugs 2017;19:325-38.

3. Kashikar-Zuck S, King C, Ting TV, Arnold LM. Juvenile fibromyalgia: Different from the adult chronic pain syndrome? Curr Rheumatol Rep 2016;18:19.

4. Kashikar-Zuck S, Ting TV. Juvenile fibromyalgia: current status of research and future developments. Nat Rev Rheumatol 2014;10:89-96.

5. Sherry DD, Brake L, Tress JL, Sherker J, Fash K, Ferry K, et al. The Treatment of Juvenile Fibromyalgia with an Intensive Physical and Psychosocial Program. J Pediatr 2015;167:731-7.

6. Ting TV, Barnett K, Lynch-Jordan A, Whitacre C, Henrickson M, Kashikar-Zuck S. 2010 American College of Rheumatology Adult Fibromyalgia Criteria for Use in an Adolescent Female Population with Juvenile Fibromyalgia. J Pediatr 2016;169:181-7.

7. Durmaz Y, Alayli G, Canbaz S, Zahiroglu Y, Bilgici A, Ilhanli I, et al. Prevalence of juvenile fibromyalgia syndrome in an urban population of Turkish adolescents: impact on depressive symptoms, quality of life and school performance. Chin Med J (Engl) 2013;126:3705-11.

8. Cunningham NR, Tran ST, Lynch-Jordan AM, Ting TV, Sil S, Strotman D, et al. Psychiatric disorders in young adults diagnosed with juvenile fibromyalgia in adolescence. J Rheumatol 2015;42:2427-33.

9. Kashikar-Zuck S, Cunningham N, Sil S, Bromberg $\mathrm{MH}$, Lynch-Jordan AM, Strotman D, et al. Longterm outcomes of adolescents with juvenileonset fibromyalgia in early adulthood. Pediatrics 2014;133:592-600.

10. Bárcia RN, Valle NS, McLeod JD. Caspase involvement in RIP-associated CD95-induced T cell apoptosis. Cell Immunol 2003;226:78-85.

11. Goulart R, Pessoa C, Lombardi I Junior. Psychological aspects of juvenile fibromyalgia syndrome: a literature review. Rev Bras Reumatol Engl Ed 2016;56:69-74.

12. Jastrowski Mano KE. School anxiety in children and adolescents with chronic pain. Pain Res Manag 2017;2017:8328174.

13. Agoston AM, Gray LS, Logan DE. Pain in school: Patterns of pain-related school impairment among adolescents with primary pain conditions, juvenile idiopathic arthritis pain, and pain-free peers. Children (Basel) 2016;3.

14. Roth-Isigkeit A, Thyen U, Stöven H, Schwarzenberger J, Schmucker P. Pain among children and adolescents: restrictions in daily living and triggering factors. Pediatrics 2005;115:152-62.

15. Wolfe F, Smythe HA, Yunus MB, Bennett RM, Bombardier C, Goldenberg DL, et al. The American College of Rheumatology 1990 Criteria for the Classification of Fibromyalgia. Report of the Multicenter Criteria Committee. Arthritis Rheum 1990;33:160-72.

16. Yunus MB, Masi AT. Juvenile primary fibromyalgia syndrome. A clinical study of thirty-three patients and matched normal controls. Arthritis Rheum 1985;28:138-45.

17. Kovacs M. The Children's Depression, Inventory (CDI). Psychopharmacol Bull 1985;21:995-8.

18. Öy B. Çocuklar için depresyon ölçeği: Geçerlilik ve güvenirlik çalışması. Türk Psikiyatri Dergisi 1991;2:132-6.

19. Varni JW, Burwinkle TM, Seid M, Skarr D. The PedsQL 4.0 as a pediatric population health measure: feasibility, reliability, and validity. Ambul Pediatr 2003;3:329-41.

20. Varni JW, Seid M, Kurtin PS. PedsQL 4.0: reliability and validity of the Pediatric Quality of Life Inventory version 4.0 generic core scales in healthy and patient populations. Med Care 2001;39:800-12.

21. Memik NC, Ağaoğlu B, Coşkun A, Karakay I. Çocuklar için yaşam kalitesi ölçeğinin 8-12 yaş çocuk formunun geçerlik ve güvenirliği. Turk J Child Adolesc Ment Health 2008;15:87-98.

22. Memik NC, Ağaoğlu B, Coşkun A, Üneri OS, Karakaya I. Çocuklar için yaşam kalitesi ölçeğinin 13-18 yaş ergen formunun geçerlik ve güvenilirliği. Türk Psikiyatri Dergisi 2007;18:353-63.

23. Tran ST, Thomas S, DiCesare C, Pfeiffer M, Sil $\mathrm{S}$, Ting TV, et al. A pilot study of biomechanical assessment before and after an integrative training program for adolescents with juvenile fibromyalgia. Pediatr Rheumatol Online J 2016;14:43.

24. Kashikar-Zuck S, Tran ST, Barnett K, Bromberg MH, Strotman D, Sil S, et al. A Qualitative examination of a new combined cognitive-behavioral and neuromuscular training intervention for juvenile fibromyalgia. Clin $\mathrm{J}$ Pain 2016;32:70-81.

25. Arnold LM, Bateman L, Palmer RH, Lin Y. Preliminary experience using milnacipran in patients with juvenile fibromyalgia: lessons from a clinical trial program. Pediatr Rheumatol Online J 2015;13:27.

26. Cassisi G, Sarzi-Puttini P, Alciati A, Casale R, Bazzichi L, Carignola R, et al. Symptoms and signs in fibromyalgia syndrome. Reumatismo 2008;60:15-24.

27. Lynch-Jordan AM, Sil S, Bromberg M, Ting TV, Kashikar-Zuck S. Cross-sectional study of young adults diagnosed with juvenile fibromyalgia: social support and its impact on functioning and mood. $\mathrm{J}$ Adolesc Health 2015;57:482-7.

28. Offenbächer M, Kohls N, Walker L, Hermann C, Hügle $\mathrm{B}$, Jäger $\mathrm{N}$, et al. Functional limitations in children and adolescents suffering from chronic pain: validation and psychometric properties of the German Functional Disability Inventory (FDI-G). Rheumatol Int 2016;36:1439-48.

29. Kashikar-Zuck S, Vaught MH, Goldschneider KR, Graham TB, Miller JC. Depression, coping, and functional disability in juvenile primary fibromyalgia syndrome. J Pain 2002;3:412-9.

30. Pflug V, Schneider S. School absenteeism: An online survey via social networks. Child Psychiatry Hum Dev 2016;47:417-29. 
31. Stempel H, Cox-Martin M, Bronsert M, Dickinson LM, Allison MA. Chronic school absenteeism and the role of adverse childhood experiences. Acad Pediatr 2017;17:837-43.

32. Kashikar-Zuck S, Johnston M, Ting TV, Graham BT, Lynch-Jordan AM, Verkamp E, et al. Relationship between school absenteeism and depressive symptoms among adolescents with juvenile fibromyalgia. J Pediatr Psychol 2010;35:9961004.

33. Reid GJ, Lang BA, McGrath PJ. Primary juvenile fibromyalgia: psychological adjustment, family functioning, coping, and functional disability. Arthritis Rheum 1997;40:752-60.
34. Gauntlett-Gilbert J, Eccleston C. Disability in adolescents with chronic pain: Patterns and predictors across different domains of functioning. Pain 2007;131:132-41.

35. Logan DE, Simons LE, Stein MJ, Chastain L. School impairment in adolescents with chronic pain. J Pain 2008;9:407-16.

36. Bennett RM, Jones J, Turk DC, Russell IJ, Matallana L. An internet survey of 2,596 people with fibromyalgia. BMC Musculoskelet Disord 2007;8:27.

37. Senna MK, Ahmad HS, Fathi W. Depression in obese patients with primary fibromyalgia: the mediating role of poor sleep and eating disorder features. Clin Rheumatol 2013;32:369-75. 